\title{
Normal Vibrational Mode Analysis and Assignment of Benzimidazole by ab Initio and Density Functional Calculations and Polarized Infrared and Raman Spectroscopy
}

\author{
M. A. Morsy, ${ }^{*}$, M. A. Al-Khaldi, ${ }^{\ddagger}$ and A. Suwaiyan ${ }^{\dagger}$ \\ Department of Chemistry, King Fahd University of Petroleum \& Minerals, Dhahran 31261, Saudi Arabia, and \\ Department of Chemistry, Girls College, Dammam, Saudi Arabia
}

Received: February 27, 2002; In Final Form: July 8, 2002

\begin{abstract}
Molecular structure and fundamental vibrational frequencies of benzimidazole (BZI) are reported using ab initio-Hartree-Fock (HF) and density functional theory (DFT) methods at different levels of calculation. Observed polarized IR and Raman fundamentals of polycrystalline, single crystal, KBr-BZI disks, and gaslike samples are analyzed and assigned by comparison to the computed values. The assignment of fundamentals shows a one-to-one correspondence between the observed and calculated fundamentals using the BLYP/6$31 \mathrm{G}^{*}$ level of calculation without applying any scaling factor except for $\mathrm{XH}$ stretching (X represents $\mathrm{C}$ or $\mathrm{N}$ ), where a 0.995 scaling factor has been used. Hydrogen bonding and its effects on some normal vibrational modes are discussed. The results show that the nonscaled BLYP/6-31G* level of calculation may be used as a reference for assessing the intermolecular hydrogen bonding effect.
\end{abstract}

\section{Introduction}

Benzimidazole (BZI) and a series of substituted BZI analogues are fundamental compounds of many important chemicals: pharmaceutical fine chemicals, ${ }^{1-7}$ polymers, ${ }^{8-11}$ and corrosion inhibitors. ${ }^{12-15}$ These different applications have attracted many experimentalists and theorists to investigate the spectroscopic properties of benzimidazole ${ }^{15-20}$ and some of its derivatives. $^{21-23}$

Several vibrational studies of BZI were performed on its $\mathrm{KBr}$ disk, ${ }^{18}$ solid and solution, ${ }^{24} \mathrm{KBr}$ mull, ${ }^{19}$ melt and single crystal, ${ }^{17}$ and its gaslike phase in the Ar matrix ${ }^{25}$ to settle its modes' assignments. However, there is still some ambiguity in the assignment of certain fundamental modes due to their low intensities or extensive band overlapping. The earlier polarized IR and Raman results ${ }^{17}$ resolved some of these ambiguities, but a reliable theoretical study in conjunction with these results is required to shed more light on the analysis and assignment of the fundamentals. The successful use of ab initio Hartree-Fock (HF) computational method in our analysis of the vibrational modes of 5-methoxyindole, ${ }^{26}$ conformer stabilities' determination of thymine, ${ }^{27}$ and a liquid crystalline system ${ }^{28}$ motivated us to advance our earlier analysis of the polarized IR and Raman results ${ }^{17}$ of benzmidazole.

In this study, we compare the predictive abilities of different theoretical methods using various basis sets in reproducing the experimental molecular geometry and vibrational results. The calculations of molecular structure and normal vibrational mode analyses of BZI were performed at Hartree-Fock (HF) and two density functional theory (DFT) methods, namely, Becke-LeeYang-Parr (BLYP) and Becke 3-Lee-Yang-Parr (B3LYP), using the $3-21 \mathrm{G}$ and $6-31 \mathrm{G}^{*}$ basis sets. The results confirm that DFT with a specific basis set is sufficiently powerful to predict fundamentals even without using any scaling factor

\footnotetext{
* To whom all correspondence should be addressed. E-mail: mamorsy@ kfupm.edu.sa.

King Fahd University of Petroleum \& Minerals.

$\doteqdot$ Girls College.
}

except for XH stretching modes, where a 0.995 scaling factor was used. Moreover, the thorough analysis of the reported ${ }^{17,25}$ polarized Raman spectra from a single crystal of BZI and its well-resolved FT-IR spectra of the gaslike state and of KBr disks rationalized the effect of the intermolecular hydrogen bonding on some fundamental modes.

\section{Experimental Section}

Benzimidazole (BZI) was obtained from Fluka and was used after repeated crystallization from an ethanol-water mixture to remove particulate and colored impurities. IR spectra of a series of $\mathrm{BZI}-\mathrm{KBr}$ disks were recorded at room temperature on a Perkin-Elmer 16PC FT-IR spectrometer at $2 \mathrm{~cm}^{-1}$ resolution. Vibrational spectra in Figures 1 and 2 show that the extensive band overlapping in the IR and broadening problems could be overcome by the proper procedure of dilution, grinding, and preparation of $\mathrm{BZI}-\mathrm{KBr}$ disks. This procedure has produced clear IR spectra (e.g., spectra C and D of Figures 1 and 2), which exhibited a one-to-one correspondence of fundamentals with the Raman spectrum (spectrum F in both Figures) of the polycrystalline BZI. ${ }^{17}$ These reported IR spectra have also comparable band features to IR spectra of BZI in the gaslike state (spectrum $\mathrm{E}$ in both Figures). ${ }^{25}$

Polarized IR and Raman spectra of polycrystalline BZI and polarized Raman spectra of a large single crystal of BZI were reported in our earlier study. ${ }^{17}$ The high-resolution polarized Raman spectra from a single crystal of BZI has been used to identify some of the poorly resolved or weakly represented fundamentals from the Raman spectrum of polycrystalline BZI in the $100-1700 \mathrm{~cm}^{-1}$ range (Figure $1 \mathrm{~S}$ ).

\section{Method of Calculations}

Calculations on BZI were performed at the LCAO-MO-SCF restricted Hartree-Fock (HF) and density functional theory (DFT) levels using Becke-Lee-Yang-Parr (BYLP) and Becke's nonlocal three-parameter exchange and correlated funcational with Lee-Yang-Parr correlation (B3YLP) func- 


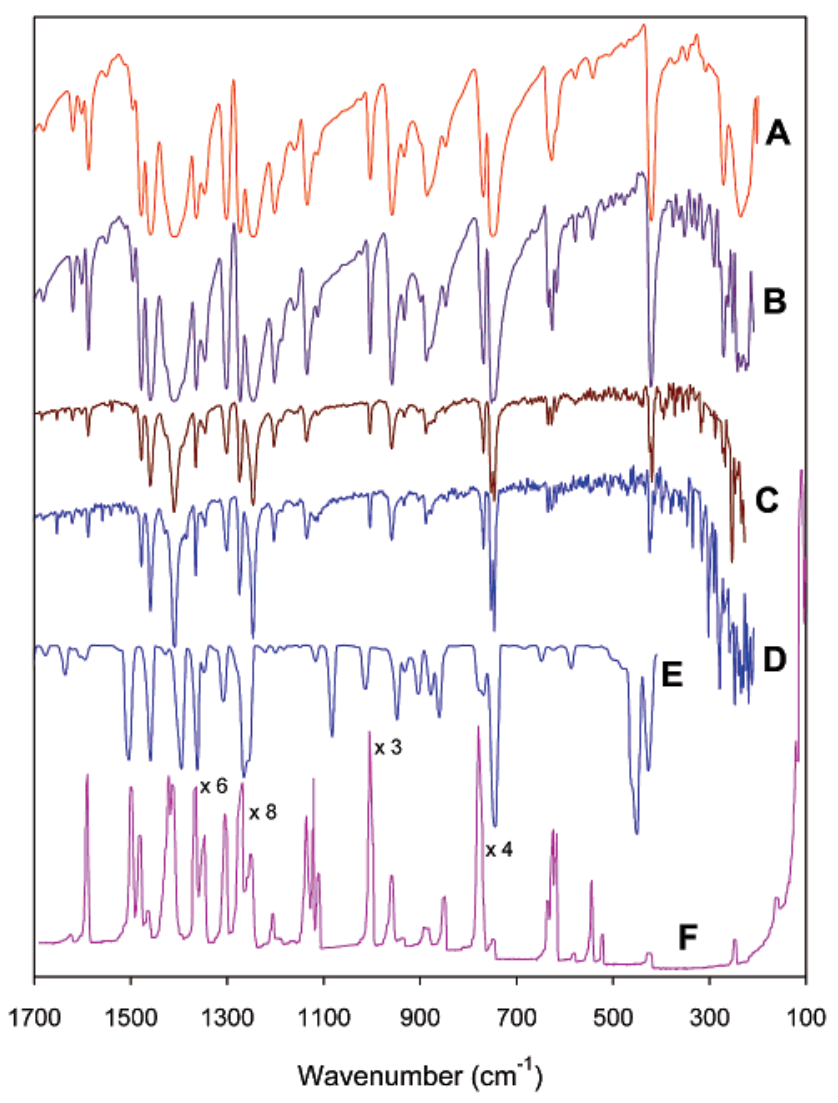

Figure 1. Vibrational spectra of benzimidazole: (A-D) FT-IR of polycrystalline samples at different concentration from high to low, respectively. (E) FT-IR of gaslike sample trapped in argon matrix. (F) Raman of polycrystalline sample. Expansion notation (e.g., $\times 3$ ) has to be applied to the adjacent vibrational band on the left to get the original intensity.

tional methods. The runs were executed on a relatively fast personal computer. The optimized molecular geometry of BZI was obtained without any structural constraint on the planarity using the most common basis sets, namely $3-21 \mathrm{G}^{*}$ and $6-31 \mathrm{G}^{*}$, with the GAUSSIAN 98W program. ${ }^{29}$ A planar geometry was found to be the most stable one. In addition to the reported ${ }^{30}$ X-ray molecular parameters of BZI, all the estimated bond lengths and angles of the optimized BZI molecule are listed in Table 1.

As expected, the computed fundamental frequencies using $\mathrm{HF} / 3-21 \mathrm{G}^{*}$ and HF/6-31G* were overestimated by about $10-$ $12 \% .{ }^{31} \mathrm{It}$, therefore, has been advisable to scale their computed values by a single uniform factor of $0.91^{32-35}$ or $0.8929 .{ }^{36}$ However, other results on planar molecules indicated ${ }^{26,37}$ that two scaling factors of 0.9017 for in-plane modes and 0.8383 for out-of-plane modes could be used to bring closer the calculated and observed frequencies. On the other hand, computational results on fundamentals using DFT methods showed that these methods reproduce experimental vibrational frequencies with higher accuracy than do the HF and MP2 methods. ${ }^{37-44}$ For example, results on predicting the fundamentals of 20 small molecules (e.g., benzene, ether, etc., whose vibrational spectra are exactly assigned) by Rauhut and Pulay ${ }^{42}$ using BLYP and B3LYP functional methods derived uniform scaling factors of 0.995 and 0.963 , respectively.

In our analysis, the HF-computed BZI vibrational modes have been scaled with the proposed ${ }^{26,37}$ scaling factors of the planar system. For DFT-computed fundamentals, the proposed ${ }^{42}$ scaling factor of 0.963 was very suitable for scaling at the B3LYP level of calculations, whereas no scaling factor was required for

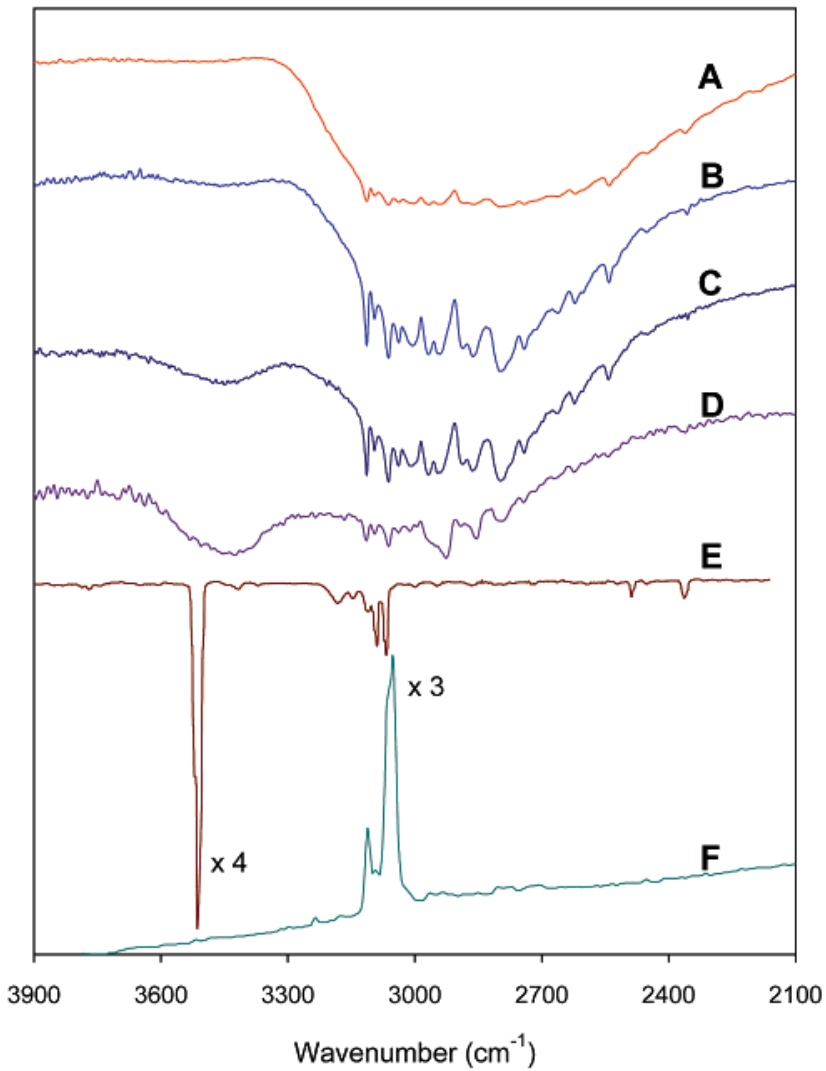

Figure 2. XH stretching vibrational spectra of benzimidazole: (AD) FT-IR of polycrystalline samples at different concentration from high to low, respectively. (E) FT-IR of gaslike sample trapped in argon matrix. (F) Raman of polycrystalline sample. Expansion notation (e.g., $\times 3$ ) has to be applied to the adjacent vibrational band on the left to get the original intensity.

BLYP-computed fundamentals except for the $\mathrm{X}-\mathrm{H}$ stretching modes where the 0.995 scaling factor was implemented.

HyperChem ${ }^{45}$ under MS-Windows has been used to display all the vibrational modes associated with each calculated spectral line. The computed IR spectrum has been produced from Gaussian output files by FreqChk utilities ${ }^{46}$ in the GAUSSIAN 98W package. The HyperChem vibrational spectrum with active IR vector rendering has been used to graphically display the normal modes associated with individual vibrations. For the sake of an informative graphical display, representative IR vectors, which have strengths of $20 \%$ or higher, have been displayed for all the BZI-fundamentals.

\section{Results and Discussion}

Geometric Structure. Molecular geometry and numbering of atoms of benzimidazole (BZI) are depicted in Figure 3, which also shows some of the estimated structure parameters and experimental bond lengths and bond angles. Although it is wellknown that the HF method underestimates bond lengths, ${ }^{36}$ the $\mathrm{HF} / 6-31 \mathrm{G}^{*}$ method of calculation has the least bond length discrepancy (less than $0.01 \AA$ ) relative to the X-ray values (Figure 4A). On the other hand, the BLYP/3-21G* method of calculation gives the largest discrepancy with $\mathrm{X}$-ray values. Closer examination of the bond lengths in Figure 4A estimated using $\mathrm{HF} / 6-31 \mathrm{G}^{*}$ relative to the X-ray values shows that large deviations are observed in the bond lengths of C5-C6, N1$\mathrm{C} 7$, and $\mathrm{C} 7-\mathrm{N} 2$. Bonds $\mathrm{C} 5-\mathrm{C} 6$ and $\mathrm{C} 7-\mathrm{N} 2$ are stretched whereas $\mathrm{N} 1-\mathrm{C} 7$ is shortened. These deviations may be attributed to the solid state intermolecular interactions, particularly 
TABLE 1: Optimized and X-ray Geometrical Parameters of BZI, Lengths in Ångstroms and Angles in Degrees

\begin{tabular}{|c|c|c|c|c|c|c|c|}
\hline \multicolumn{2}{|c|}{ parameters $^{a}$} & \multicolumn{2}{|c|}{$\mathrm{HF}$} & \multicolumn{2}{|c|}{ BLYP } & \multicolumn{2}{|c|}{ B3LYP } \\
\hline name & X-ray & $3-21 G^{*}$ & $6-31 G^{*}$ & $3-21 G^{*}$ & $6-31 G^{*}$ & $3-21 G^{*}$ & $6-31 G^{*}$ \\
\hline \multicolumn{8}{|c|}{ A. Bond Length } \\
\hline $\mathrm{C}_{1}-\mathrm{C}_{2}$ & 1.389 & 1.38561 & 1.39255 & 1.40696 & 1.40957 & 1.3969 & 1.40044 \\
\hline $\mathrm{C}_{2}-\mathrm{C}_{3}$ & 1.386 & 1.37563 & 1.37697 & 1.40248 & 1.40226 & 1.3913 & 1.39084 \\
\hline $\mathrm{C}_{3}-\mathrm{C}_{4}$ & 1.401 & 1.40117 & 1.4024 & 1.42058 & 1.41921 & 1.41084 & 1.41012 \\
\hline $\mathrm{C}_{4}-\mathrm{C}_{5}$ & 1.378 & 1.37723 & 1.37815 & 1.40426 & 1.40334 & 1.3923 & 1.39204 \\
\hline $\mathrm{C}_{5}-\mathrm{C}_{6}$ & 1.401 & 1.38685 & 1.39002 & 1.40519 & 1.40568 & 1.39491 & 1.39622 \\
\hline $\mathrm{C}_{6}-\mathrm{C}_{1}$ & 1.392 & 1.39697 & 1.39403 & 1.43619 & 1.42985 & 1.421141 & 1.41642 \\
\hline $\mathrm{C}_{6}-\mathrm{N}_{1}$ & 1.372 & 1.38244 & 1.37662 & 1.40191 & 1.39544 & 1.39176 & 1.38473 \\
\hline $\mathrm{N}_{1}-\mathrm{C}_{7}$ & 1.346 & 1.381 & 1.36108 & 1.41 & 1.391 & 1.395 & 1.378 \\
\hline $\mathrm{C}_{7}-\mathrm{N}_{2}$ & 1.311 & 1.29092 & 1.27999 & 1.33448 & 1.32034 & 1.31993 & 1.30656 \\
\hline $\mathrm{N}_{2}-\mathrm{C}_{1}$ & 1.395 & 1.40322 & 1.38561 & 1.42259 & 1.40333 & 1.41066 & 1.39106 \\
\hline $\mathrm{C}_{2}-\mathrm{H}_{1}$ & 0.94 & 1.0702 & 1.07442 & 1.08883 & 1.09338 & 1.08162 & 1.086 \\
\hline $\mathrm{C}_{3}-\mathrm{H}_{2}$ & 1.02 & 1.0719 & 1.07579 & 1.09094 & 1.09346 & 1.08301 & 1.08639 \\
\hline $\mathrm{C}_{4}-\mathrm{H}_{3}$ & 1.07 & 1.0714 & 1.07567 & 1.09118 & 1.09452 & 1.08312 & 1.08708 \\
\hline $\mathrm{C}_{5}-\mathrm{H}_{4}$ & 0.98 & 1.0712 & 1.07569 & 1.09106 & 1.09421 & 1.08353 & 1.08704 \\
\hline $\mathrm{N}_{1}-\mathrm{H}_{5}$ & 0.9 & 0.9943 & 0.993453 & 1.02121 & 1.01847 & 1.01242 & 1.00924 \\
\hline $\mathrm{C}_{7}-\mathrm{H}_{6}$ & 1.03 & 1.0644 & 1.07263 & 1.08443 & 1.09004 & 1.07709 & 1.08336 \\
\hline \multicolumn{8}{|c|}{ B. Bond Angle } \\
\hline $\mathrm{C}_{1} \mathrm{C}_{2} \mathrm{C}_{3}$ & 117.8 & 118.2 & 118 & 118.4 & 118.1 & 118.3 & 118.1 \\
\hline $\mathrm{C}_{2} \mathrm{C}_{3} \mathrm{C}_{4}$ & 120.9 & 120.9 & 121.2 & 121.2 & 121.4 & 121.1 & 121.4 \\
\hline $\mathrm{C}_{3} \mathrm{C}_{4} \mathrm{C}_{5}$ & 122.3 & 121.5 & 121.5 & 121.5 & 121.6 & 121.4 & 121.6 \\
\hline $\mathrm{C}_{4} \mathrm{C}_{5} \mathrm{C}_{6}$ & 116.1 & 117.2 & 116.8 & 117.2 & 116.6 & 117.3 & 116.7 \\
\hline $\mathrm{C}_{5} \mathrm{C}_{6} \mathrm{C}_{1}$ & 122.4 & 121.7 & 122.4 & 121.9 & 122.6 & 121.8 & 122.6 \\
\hline $\mathrm{C}_{6} \mathrm{C}_{1} \mathrm{C}_{2}$ & 120.6 & 120.4 & 120 & 119.9 & 119.7 & 120 & 119.7 \\
\hline $\mathrm{C}_{1} \mathrm{C}_{6} \mathrm{~N}_{1}$ & 105.8 & 105.3 & 104.6 & 104.9 & 104.4 & 105 & 104.4 \\
\hline $\mathrm{C}_{6} \mathrm{~N}_{1} \mathrm{C}_{7}$ & 106.6 & 106.7 & 106.4 & 107.1 & 106.8 & 107.1 & 106.7 \\
\hline $\mathrm{N}_{1} \mathrm{C}_{7} \mathrm{~N}_{2}$ & 114 & 112.7 & 114.1 & 112.9 & 113.7 & 112.8 & 113.7 \\
\hline $\mathrm{C}_{7} \mathrm{~N}_{2} \mathrm{C}_{1}$ & 104.2 & 105.9 & 104.8 & 104.9 & 104.5 & 105.2 & 104.6 \\
\hline $\mathrm{N}_{2} \mathrm{C}_{1} \mathrm{C}_{6}$ & 109.5 & 109.3 & 110.1 & 110.2 & 110.6 & 109.9 & 110.5 \\
\hline $\mathrm{C}_{1} \mathrm{C}_{2} \mathrm{H}_{1}$ & 117 & 119.9 & 120.3 & 119.8 & 120.1 & 119.9 & 120.2 \\
\hline $\mathrm{C}_{2} \mathrm{C}_{3} \mathrm{H}_{2}$ & 117 & 119.9 & 119.7 & 119.7 & 119.5 & 119.7 & 119.6 \\
\hline $\mathrm{C}_{3} \mathrm{C}_{4} \mathrm{H}_{3}$ & 111 & 119.2 & 119.2 & 119.3 & 119.3 & 119.2 & 119.3 \\
\hline $\mathrm{C}_{4} \mathrm{C}_{5} \mathrm{H}_{4}$ & 121 & 121.1 & 121.3 & 120.8 & 121.3 & 120.8 & 121.3 \\
\hline $\mathrm{C}_{6} \mathrm{~N}_{1} \mathrm{H}_{5}$ & 126 & 126.8 & 127.4 & 126.2 & 126.7 & 126.4 & 126.9 \\
\hline $\mathrm{N}_{1} \mathrm{C}_{7} \mathrm{H}_{6}$ & 121 & 121.7 & 121 & 121.5 & 121 & 121.6 & 121.1 \\
\hline
\end{tabular}

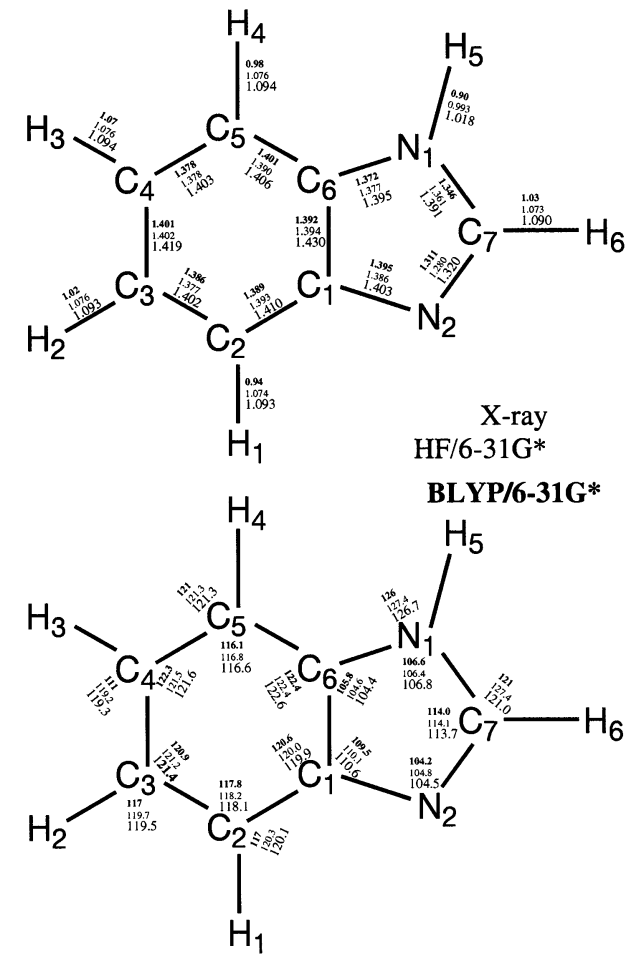

Figure 3. Observed and selected values of the calculated structural parameters of benzimidazole molecule.

the reported strong hydrogen bonding, ${ }^{30}$ which is $2.0 \AA$ long from $\mathrm{H} 5$ to $\mathrm{N} 2$.
Regarding the $\mathrm{C}-\mathrm{H}$ and $\mathrm{N}-\mathrm{H}$ bond lengths, it is wellknown ${ }^{36}$ that due to low scattering factors of hydrogen atoms in X-ray diffraction, the experimental bond lengths of $\mathrm{X}-\mathrm{H}$ bonds are much shorter than the estimated bond lengths. ${ }^{27,36}$ As expected, Figure 4B shows that most of the observed $\mathrm{C}-\mathrm{H}$ bond lengths of BZI are shorter than the estimated values. Exceptions for this trend are observed in $\mathrm{C} 4-\mathrm{H} 3$ and $\mathrm{N} 1-\mathrm{H} 5$ bond lengths that are remarkably stretched out to approach the estimated values. The prolonged $\mathrm{N} 1-\mathrm{H} 5$ bond length of the imidazole (Im) ring can be linked to the intermolecular hydrogen bonds. ${ }^{47-49}$ However, the stretch of the $\mathrm{C} 4-\mathrm{H} 3$ bond length of the benzene $(\mathrm{Bz})$ ring may be attributed to crystal packing effects.

The estimated bond angles (Figure 5) agree very well with the observed X-ray values. Discrepancies are about $0.9^{\circ}$ for bond angles except for some of the $\mathrm{Bz}-\mathrm{CCH}$ angles. The largest discrepancy of about $8^{\circ}$ is observed in the $\mathrm{C} 3 \mathrm{C} 4 \mathrm{H} 3$ bond angle. This deviation may be attributed to a crystal packing effect, namely, molecular structure strain between benzene parts of different BZI molecules (see molecules III and VI in the unit cell presentation in Figure 6), ${ }^{17}$ which is further evidence of the elongation in the $\mathrm{C} 4-\mathrm{H} 3$ bond length.

Fundamental Modes. Benzimidazole has a $C_{s}$ symmetry and 39 fundamental modes; all of them are IR and Raman active. These modes include 12-depolarized out-of-plane modes with $\mathrm{A}^{\prime \prime}$ symmetry and 27-polarized in-plane modes with $\mathrm{A}^{\prime}$ symmetry. Tables $1 \mathrm{~S}, 2 \mathrm{~S}$, and $3 \mathrm{~S}$ (Supporting Information) present a comprehensive summary of all fundamentals. These tables show the reported fundamentals of BZI and their assignments from IR spectra of $\mathrm{KBr}$ disks, ${ }^{19}$ partially oriented solid, ${ }^{17}$ a 

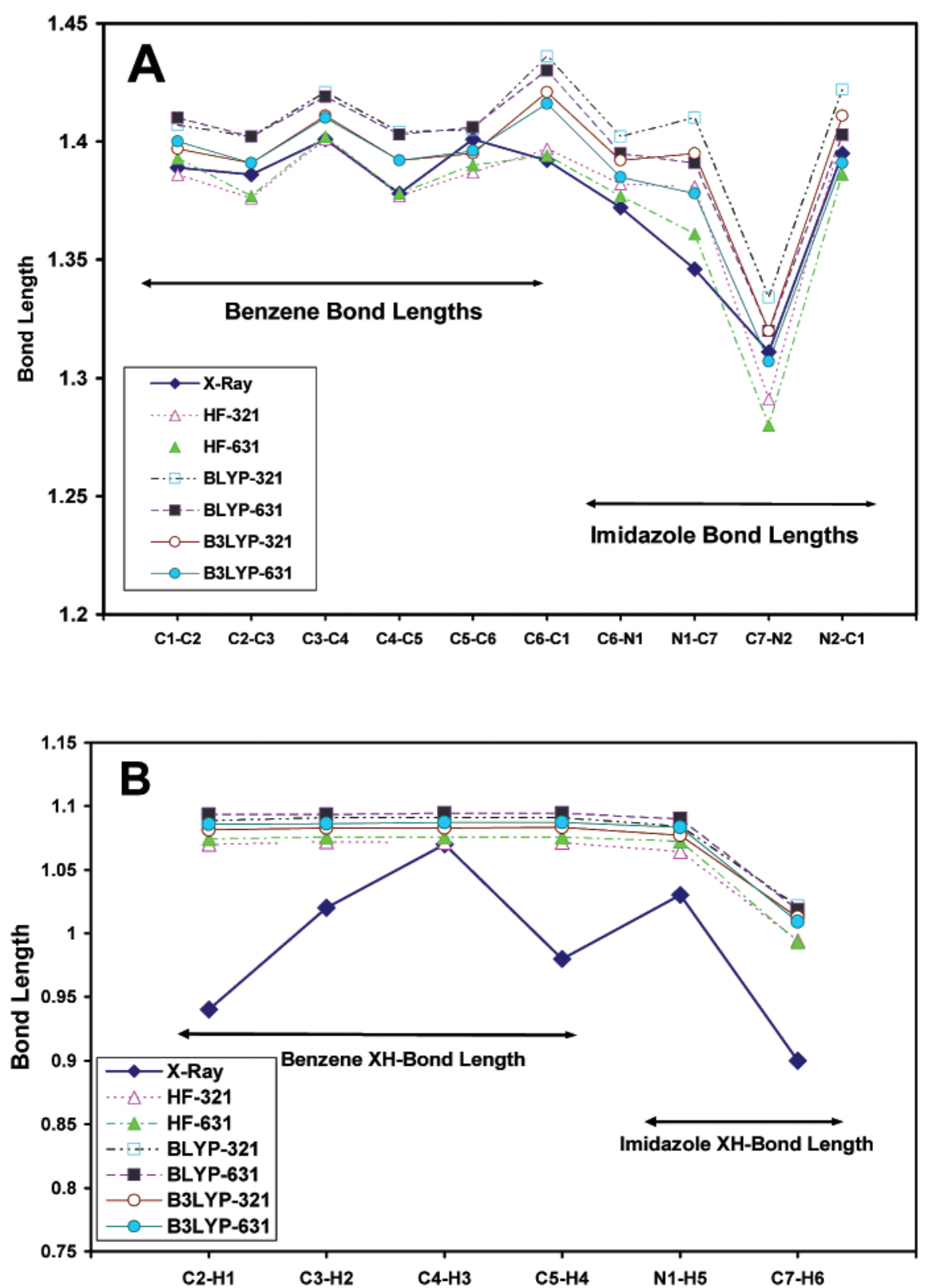

Figure 4. Observed and calculated bond lengths of benzimidazole: (A) $\mathrm{C}-\mathrm{C}$ and $\mathrm{C}-\mathrm{N}$ bond lengths; (B) $\mathrm{C}-\mathrm{H}$ and $\mathrm{N}-\mathrm{H}$ bond lengths.

gaslike phase trapped in an argon matrix, ${ }^{25}$ and observed IR values from the highly resolved absorption spectra $\mathrm{C}$ and $\mathrm{D}$ of Figures 1 and 2. Estimated values of all the fundamentals, their scaled values, intensities, and the corresponding IR vector graphical representation for the optimized geometries of single BZI molecule at each ab initio level used in this study are also included in Tables $1 \mathrm{~S}, 2 \mathrm{~S}$, and $3 \mathrm{~S}$. The observed fundamental frequencies and their best estimated values and mode assignments have been extracted from these tables and are presented in Table 2.

The polarization of the incident and scattered light has enormous effects on the intensities of vibrational modes (Figure 1S). The BZI fundamentals from these polarized spectra and Raman spectrum of BZI powder are also included in Tables $1 \mathrm{~S}$ and $2 \mathrm{~S}$. A close examination of these reported polarized Raman spectra indicates that many vibrations become weaker or even disappear as a result of the change in polarization, except for bb- and cc-polarized Raman spectra. These two spectra show the clearest identified BZI fundamentals compared to the powder sample. This is in agreement with the reported results on the oriented gas model, ${ }^{17}$ which predicts the vibrations with $\mathrm{A}^{\prime}$ symmetry will be most intense parallel to the $b$-axis whereas $\mathrm{A}^{\prime \prime}$ types vibrations will be most intense parallel to the $c$-axis.

Out-of-Plane Modes. Systematic comparison of the observed out-of-plane fundamentals of solid samples with the corresponding fundamentals of the gaslike sample (Table 2 and Figure 1) shows different correlations. For the 626 and $887 \mathrm{~cm}^{-1}$ modes, the frequency deviations, which are quite large, are about 180 and $30 \mathrm{~cm}^{-1}$, respectively. On the other hand, the correlation is quite good for the $424,578,635,746,752,902$, and 933 $\mathrm{cm}^{-1}$, modes with an average deviation of about $6 \mathrm{~cm}^{-1}$. This small deviation may indicate that these well-predicted modes exhibit no or minimal hydrogen bonding and/or crystal packing effects. Therefore, they can be considered as appropriate fundamentals among the out-of-planes modes to compare with the computed values.

A check of the computed values listed in Table $1 \mathrm{~S}$ relative to the above-mentioned modes shows that the closest estimating of these fundamentals are obtained by the BLYP/6-31G* level of calculation without applying the scaling factor. This agree- 

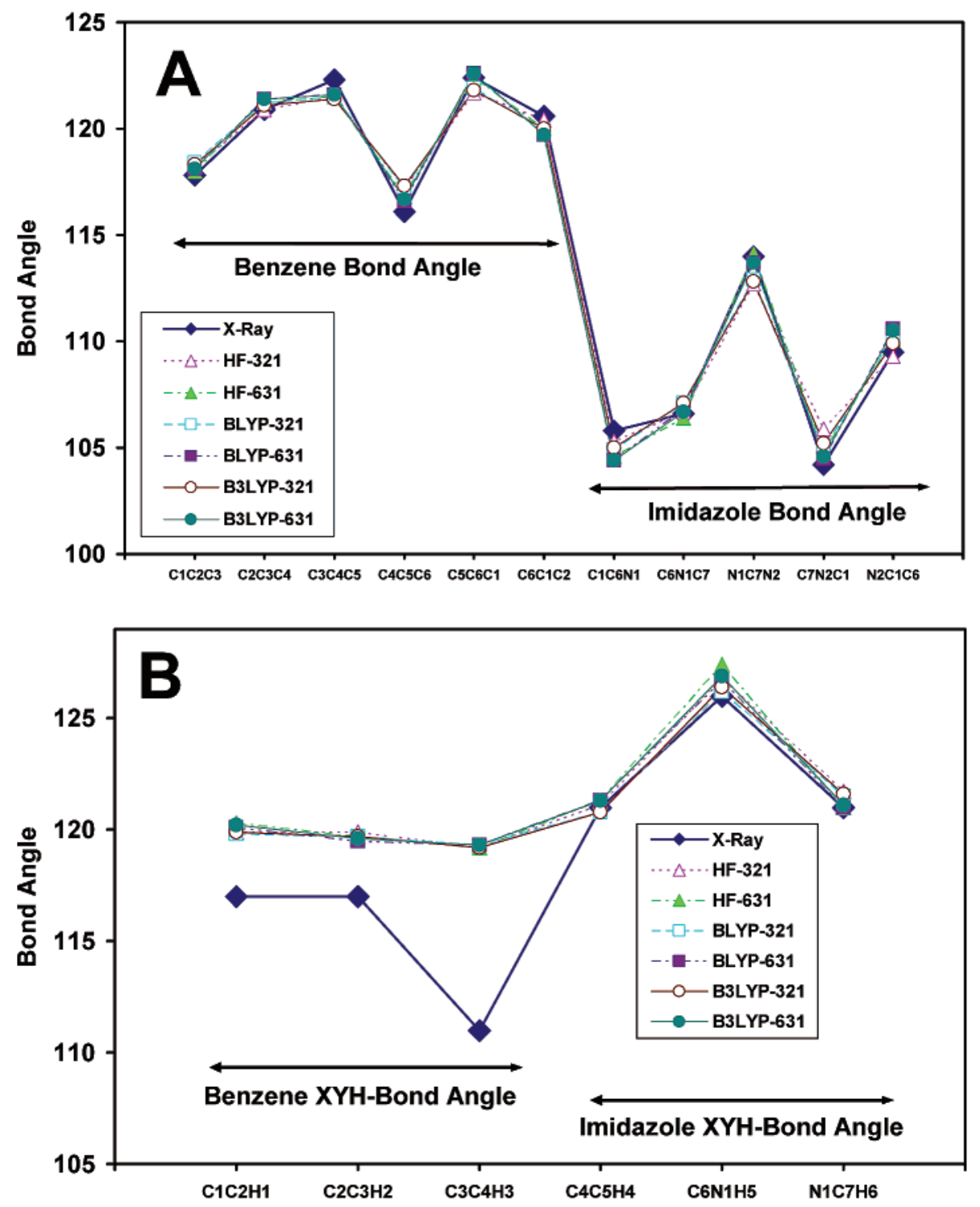

Figure 5. Observed and calculated bond angles of benzimidazole: (A) $\mathrm{C}-\mathrm{C}-\mathrm{C}$ and $\mathrm{C}-\mathrm{C}-\mathrm{N}$ bond lengths; (B) $\mathrm{C}-\mathrm{C}-\mathrm{H}$ and $\mathrm{C}-\mathrm{N}-\mathrm{H}$ bond lengths.

ment is manifested in the marginally lowest mean frequency deviation (mfd), $\overline{\mid v^{\text {exp }}-v^{\text {theor }}} \mid$, of about $6 \mathrm{~cm}^{-1}$ relative to the observed modes of the solid samples and about $10.5 \mathrm{~cm}^{-1}$ relative to the gaslike sample. The other levels of calculation, even the HF/6-31G* one, which give the best estimates of bond lengths (Figure 4A), have a much higher mfd. Some of these levels of calculation improved upon applying the recommended $^{26,37,42}$ scaling factors to them. For example, the scaled $\mathrm{HF} / 6-31 \mathrm{G}^{*}$ gives a mfd value of about $32 \mathrm{~cm}^{-1}$, whereas the nonscaled one gives a mfd value of about $40 \mathrm{~cm}^{-1}$. On the other hand, the observed low mfd between the observed out-of-plane modes of BZI and their computed values using BLYP/6-31G* causes us to limit the comparison of the remaining out-of-plane modes to the estimated results from this level of calculation (Table 2).

For the $626 \mathrm{~cm}^{-1}$ mode of vibration, the largest frequency deviation (fd) occurs relative to the gaslike sample ( $\mathrm{fd}=177$ $\mathrm{cm}^{-1}$ ) as well as to the estimated one using the BLYP/6-31G* level of calculation ( $\mathrm{fd}=220 \mathrm{~cm}^{-1}$ ). This large $\mathrm{fd}$ value is expected because this mode is attributed to $\mathrm{NH}$ out-of-plane bending ${ }^{19}$ and this $\mathrm{NH}$ is a hydrogen bonding donor site in BZI molecule (Figure 6). Moreover, comparison between its ob- served value in the gaslike sample and the corresponding calculated value shows a difference of about $40 \mathrm{~cm}^{-1}$. This difference may be attributed to the presence of the intermolecular hydrogen bonding of BZI molecules in the argon matrix. The results also indicate that the hydrogen bond effect is much weaker in the argon matrix than in the solid samples.

The second largest fd value is observed for the $887 \mathrm{~cm}^{-1}$ band, which has a deviation of about $29 \mathrm{~cm}^{-1}$ relative to the gaslike sample and $57 \mathrm{~cm}^{-1}$ for the crystalline material relative to the estimated value. The IR vector representation for this mode in Table $1 \mathrm{~S}$ and its summarized assignment in Table 2 show a large contribution of the Bz-CH wags. Therefore, this frequency deviation could be attributed to crystal packing and/ or the molecular aggregation. This deviation also correlates with the observed distortions in the $\mathrm{CH}$ bond lengths and $\mathrm{CCH}$ bond angles of the benzene part as discussed above.

Modes 242, 270, and $847 \mathrm{~cm}^{-1}$ observed in this region have no corresponding modes from the gaslike sample. However, all of them show remarkable frequency deviations for crystalline samples relative to their estimated values $\left(24,22\right.$, and $50 \mathrm{~cm}^{-1}$, respectively). According to the reported ${ }^{19}$ assignment, namely, imidazole- $\mathrm{CH}$ (Im-CH) bending of the 847 fundamental and 
TABLE 2: Observed and Estimated Frequencies $\left(\mathrm{cm}^{-1}\right)$, Relative Intensities, and Assignments of the Fundamental Modes of Benzimidazole $^{a}$

\begin{tabular}{|c|c|c|c|c|}
\hline solid $\mathrm{IR}^{b}$ & solid $\operatorname{Ram}^{c}$ & gaslike $^{d}$ & estimated frequencies ${ }^{e}$ & assignments/symmetry $f^{f}$ \\
\hline \multicolumn{5}{|c|}{ Out-of-Plane Modes } \\
\hline $242(\mathrm{~m})$ & $247(w)$ & & $218(6.66)$ & Bz \& Im CH wags (sym)/A" \\
\hline $270(\mathrm{~m})$ & $272(\mathrm{vw})$ & & $248(1.65)$ & Bz \& Im CH wags (asym)/A" \\
\hline $626(\mathrm{~m})$ & $625(\mathrm{~m})$ & 449 (vs) & $406(99.94)$ & NH wag/A" \\
\hline $424(s)$ & $424(w)$ & $425(\mathrm{~s})$ & $421(2.11)$ & mainly $\mathrm{C} 2 \mathrm{H}, \mathrm{C} 5 \mathrm{H}$, and $\mathrm{Im} \mathrm{NH}$ wags/A" \\
\hline $578(w)$ & $580(w)$ & $586(w)$ & $570(4.36)$ & mainly $\mathrm{C} 3 \mathrm{H}, \mathrm{C} 4 \mathrm{H}$, and $\mathrm{NH}$ wags/A" \\
\hline $635(\mathrm{~m})$ & $636(\mathrm{~m})$ & $647(w)$ & $630(2.11)$ & mainly Im CH \& NH wags (asym)/A" \\
\hline 746 (vs) & $746(w)$ & 743 (vs) & $731(45.57)$ & Bz CH's wags (sym)/A" \\
\hline $752(\mathrm{vs})$ & $755(w)$ & $766(\mathrm{~m})$ & $750(3.80)$ & mainly Bz CH's wags (asym)/A" \\
\hline $847(w)$ & $848(w)$ & & $797(8.79)$ & Im CH wag/A" \\
\hline $887(\mathrm{~m})$ & $890(w)$ & $860(\mathrm{~m})$ & $830(1.85)$ & Bz CH's and Im CH wags/A" \\
\hline $902(w)$ & $905(\mathrm{vw})$ & $903(\mathrm{~m})$ & $890(1.79)$ & mainly $\mathrm{C} 2 \mathrm{H}, \mathrm{C} 3 \mathrm{H}$, and $\mathrm{C} 5 \mathrm{H}$ wags/A" \\
\hline $933(w)$ & $934(w)$ & $931(\mathrm{w})$ & $933(0.06)$ & Bz CH's wags (asym)/A" \\
\hline \multicolumn{5}{|c|}{ In-Plane Modes } \\
\hline $419(\mathrm{~s})$ & $418(w)$ & $417(\mathrm{~m})$ & $405(7.05)$ & $\mathrm{Bz}$ and Im rings bending/ $\mathrm{A}^{\prime}$ \\
\hline $542(w)$ & $544(\mathrm{~m})$ & $538(\mathrm{vw})$ & $537(0.15)$ & $\mathrm{Bz}$ and $\mathrm{Im}$ rings stretching/ $\mathrm{A}^{\prime}$ \\
\hline $618(\mathrm{~m})$ & $617(\mathrm{~m})$ & $621(\mathrm{vw})$ & $610(0.05)$ & bending $\&$ bond stretching (asym) $/ \mathrm{A}^{\prime}$ \\
\hline $768(s)$ & 778 (vs) & $780(\mathrm{~m})$ & $767(3.89)$ & angle bending \& bond stretching (sym)/ $\mathrm{A}^{\prime}$ \\
\hline $876(\mathrm{~m})$ & $881(w)$ & $877(\mathrm{~m})$ & $863(3.39)$ & mainly $\mathrm{C} 2 \mathrm{H}, \mathrm{C} 5 \mathrm{H}$, and $\mathrm{C} 7 \mathrm{H}$ bending/ $\mathrm{A}^{\prime}$ \\
\hline $958(\mathrm{~s})$ & $958(w)$ & $947(\mathrm{~s})$ & $912(1.85)$ & mainly $\mathrm{C} 2 \mathrm{H}$ and $\mathrm{NH}$ bending $/ \mathrm{A}^{\prime}$ \\
\hline $1005(\mathrm{~m})$ & 1004 (vs) & $1011(\mathrm{~m})$ & $1005(3.14)$ & Bz CH's bending (sym)/A' \\
\hline $1134(\mathrm{~s})$ & $1135(\mathrm{~s})$ & $1082(\mathrm{~s})$ & $1061(14.89)$ & Im $\mathrm{CH}$ and $\mathrm{NH}$ bending/ $\mathrm{A}^{\prime}$ \\
\hline $1112(\mathrm{w})$ & $1110(\mathrm{~m})$ & $1115(w)$ & $1103(1.24)$ & $\mathrm{Bz}$ CH's and Im $\mathrm{CH}$ bending/A' \\
\hline $1158(\mathrm{w})$ & $1163(\mathrm{vw})$ & $1163(\mathrm{vw})$ & $1151(2.57)$ & Bz CH's bending (asym)/A' \\
\hline $1202(\mathrm{~m})$ & $1204(w)$ & $1199(w)$ & $1170(1.23)$ & Im XH's, $\mathrm{C} 2 \mathrm{H}, \mathrm{C} 3 \mathrm{H}$, and $\mathrm{C} 5 \mathrm{H}$ bending (asym) $/ \mathrm{A}^{\prime}$ \\
\hline 1246 (vs) & $1250(\mathrm{~m})$ & 1254 (vs) & $1241(22.07)$ & $\mathrm{Im} \mathrm{XH}$ 's, $\mathrm{C} 3 \mathrm{H}$, and $\mathrm{C} 4 \mathrm{H}$ bending $(\mathrm{sym}) / \mathrm{A}^{\prime}$ \\
\hline 1274 (vs) & 1277 (vs) & 1264 (vs) & $1253(26.83)$ & Im XH's, $\mathrm{C} 2 \mathrm{H}, \mathrm{C} 3 \mathrm{H}$, and $\mathrm{C} 5 \mathrm{H}$ bending $(\mathrm{sym}) / \mathrm{A}^{\prime}$ \\
\hline $1300(\mathrm{~s})$ & $1304(\mathrm{~m})$ & $1306(\mathrm{~m})$ & $1299(5.11)$ & $\mathrm{Bz} \mathrm{CH}$ 's and Im $\mathrm{CH}$ bending/A' \\
\hline $1345(\mathrm{w})$ & $1345(\mathrm{~m})$ & $1346(\mathrm{~m})$ & $1349(36.89)$ & Im XH's, $\mathrm{C} 2 \mathrm{H}$, and $\mathrm{C} 3 \mathrm{H}$ bending $(\mathrm{sym}) / \mathrm{A}^{\prime}$ \\
\hline 1410 (vs) & $1412(s)$ & 1394 (vs) & $1390(9.66)$ & Im XH's, $\mathrm{C} 2 \mathrm{H}, \mathrm{C} 4 \mathrm{H}$, and $\mathrm{C} 5 \mathrm{H}$ bending (asym) $/ \mathrm{A}^{\prime}$ \\
\hline $1459(\mathrm{w})$ & $1463(\mathrm{w})$ & $1458(\mathrm{~s})$ & $1445(22.44)$ & Bz CH's and Im XH's bending (sym)/ $\mathrm{A}^{\prime}$ \\
\hline $1478(\mathrm{~s})$ & $1480(\mathrm{~m})$ & 1494 (sh) & $1478(12.70)$ & $\mathrm{Bz} \mathrm{CH}$ 's and $\mathrm{C} 7 \mathrm{H}$ bending and $\mathrm{N} 2 \mathrm{C} 7 \mathrm{St} / \mathrm{A}^{\prime}$ \\
\hline $1494(\mathrm{~m})$ & $1498(\mathrm{~m})$ & 1503 (vs) & $1491(8.50)$ & Bz CH's and Im XH's bending (asym)/A' \\
\hline $1588(\mathrm{~m})$ & $1590(\mathrm{~s})$ & $1593(w)$ & $1576(2.93)$ & $\mathrm{C} 4 \mathrm{H}$ and $\mathrm{NH}$ bending and $\mathrm{Bz} \mathrm{CC}$ 's St/A' \\
\hline $1620(w)$ & $1623(w)$ & 1621 (vw) & $1613(6.29)$ & Bz and Im XH's bending and CC's St/A' \\
\hline \multicolumn{5}{|c|}{ XH Stretching Modes } \\
\hline $3062(w)$ & & $3066(w)$ & $3098[3083](0.16)$ & $\mathrm{Bz} \mathrm{C} 3 \mathrm{H}, \mathrm{C} 4 \mathrm{H}$, and $\mathrm{C} 5 \mathrm{H}$ stretching (asym)/A' \\
\hline $2926(\mathrm{~m})$ & $2930(w)$ & $3088(\mathrm{~m})$ & $3108[3092](18.01)$ & $\mathrm{Bz} \mathrm{C} 3 \mathrm{H}$ and $\mathrm{C} 5 \mathrm{H}$ stretching/ $\mathrm{A}^{\prime}$ \\
\hline $3094(w)$ & $3091(w)$ & 3095 (sh) & $3120[3104](33.70)$ & $\mathrm{Bz} \mathrm{C} 3 \mathrm{H}, \mathrm{C} 4 \mathrm{H}$, and $\mathrm{C} 5 \mathrm{H}$ stretching $(\mathrm{sym}) / \mathrm{A}^{\prime}$ \\
\hline $3115(\mathrm{~m})$ & $3112(\mathrm{~m})$ & $3114(\mathrm{w})$ & $3131[3115](17.57)$ & $\mathrm{Bz} \mathrm{C} 2 \mathrm{H}, \mathrm{C} 3 \mathrm{H}$, and $\mathrm{C} 4 \mathrm{H}$ stretching/A' \\
\hline $3038(w)$ & 3021 (sh) & $3145(w)$ & $3172[3156](5.62)$ & Im $\mathrm{CH}$ stretching/A' \\
\hline 3423 (b) & 3055 (vs) & 3509 (vs) & $3532[3514](30.74)$ & Im NH stretching/A' \\
\hline
\end{tabular}

${ }^{a}$ Abbreviations: vs, very strong; s, strong; m, medium; w, weak; vw, very weak; sh, shoulder; f, fundamental; A', symmetry; p, polarized; sym, symmetrical; asym, asymmetric. ${ }^{b}$ IR of $\mathrm{KBr}$ disks. ${ }^{c}$ Raman of powder. ${ }^{d}$ FT-IR of gaslike BZI in Ar matrix. ${ }^{e}$ Estimated vibrational modes using BLYP/6-31G* [its scaled value] (its intensity in $\mathrm{km} / \mathrm{mol}$ ). ${ }^{f}$ Summary of the estimated graphical representation/estimated mode symmetry.

its estimated mode assignment in Table 2, the large fd value is expected because of the hydrogen bonding effect in the Im ring. The IR vector representation for the other modes (242 and 270 fundamentals) may relate the observed fd values to combined effects of hydrogen bonding and the crystal packing factors in BZI intermolecular system.

In-Plane Modes. Table $2 \mathrm{~S}$ includes in-plane vibrational modes other than $\mathrm{CH}$ and $\mathrm{NH}$ stretching. These modes have been observed and located within the IR spectral range 100$1700 \mathrm{~cm}^{-1}$. The summary of the assignment of these modes from Figures 1 and $1 \mathrm{~S}$ and the calculated values in Table 2 shows that these fundamentals also have different correlations between the solid and the gaslike samples. This different correlation is much clearer between the observed and estimated values using BLYP/6-31G* level of calculation.

Comparison between the observed in-plane modes summarized in Table 2 and the calculated fundamentals using BLYP/ 6-31G* level of calculation shows good agreement in 16 modes. The mfd values of solid versus calculated and gaslike versus calculated frequencies are 6.4 and $11 \mathrm{~cm}^{-1}$, respectively. On the other hand, the rest of the in-plane modes, namely 958, 1134,
1202,1274 , and $1410 \mathrm{~cm}^{-1}$ give large fd values. The values of these deviations are as follows: 46, 73, 32, 21, and $20 \mathrm{~cm}^{-1}$, respectively.

The observed largest fd values for the 958 and $1134 \mathrm{~cm}^{-1}$ modes are expected because they are related to the hydrogen bonding site in the BZI molecule. This is in good agreement with the assignment of these modes as Im-ring in-plane and $\mathrm{NH}$ in-plane vibrational bending, ${ }^{19}$ respectively. Moreover, comparison of the observed frequencies of these modes in the gaslike state and the corresponding calculated values shows a difference of about 35 and $21 \mathrm{~cm}^{-1}$, respectively. These deviations are further evidence of the presence of the intermolecular hydrogen bonding of BZI molecules in the argon matrix but with a much weaker effect than the solid samples.

Smaller fd values observed in the case of modes 1202, 1274, and $1410 \mathrm{~cm}^{-1}$ may indicate that they are related to the same effect. All of them have been assigned as benzene- $\mathrm{CH}(\mathrm{Bz}-$ $\mathrm{CH})$ in-plane bends. ${ }^{19}$ Therefore; these deviations may be further evidence of the effect of crystal packing and/or the molecular aggregation. They also confirm the observed distortions in the 


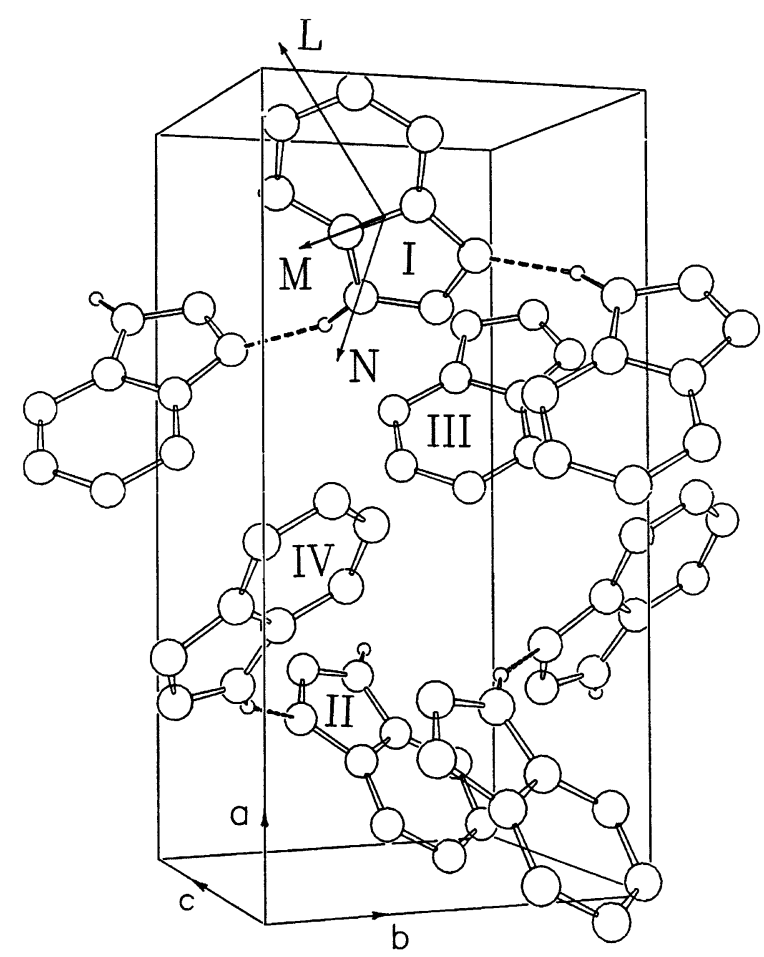

Figure 6. Benzimidazole unit cell with molecular axis frame (L, M, N).

$\mathrm{CH}$ bond lengths and $\mathrm{CCH}$ bond angles of the benzene part, as discussed above.

The summary of the in-plane results in Table $2 \mathrm{~S}$ validates the earlier observation on the different level of calculations. The nonscaled BLYP/6-31G* level of calculation shows the smallest mfd values relative to the other levels. The mfd values of the solid and gaslike cases relative to the calculated fundamentals (about 6 and $11 \mathrm{~cm}^{-1}$, respectively) are the same for both outof-plane and in-plane modes.

XH Stretching Modes. The observed spectra of these vibrational modes in solid and gaslike states are presented in Figure 2. Bands due to these modes have very different features from spectrum A down to spectrum D. For example, extensive band broadening and overlapping takes place in spectrum A that is gradually reduced by dilution until the most resolved one in spectrum D. This effect may be correlated with strong solute-solute interaction between BZI molecules. The weakness of this interaction is confirmed by the observation of band resolution in spectra $\mathrm{C}$ and $\mathrm{D}$ in Figures 1 and 2 . It is also observed that the dilution process intensifies a broad IR band at about $3423 \mathrm{~cm}^{-1}$. This band may be correlated with the $\mathrm{NH}$ stretching vibration, and its broadening is related to the intermolecular hydrogen bonding effect. The summary in Table 2 shows the fd values of the $3423 \mathrm{~cm}^{-1}$ mode relative to the gaslike sample (about $91 \mathrm{~cm}^{-1}$ ) and to the calculated fundamentals (about $109 \mathrm{~cm}^{-1}$ ). These deviations confirm the relation between this mode and the intermolecular hydrogen bonding effect. The broadening properties of this mode may indicate that the hydrogen bonding is not the only intermolecular solutesolute interaction factor that is responsible for the observed extensive band broadness in spectrum A of Figure 2. Thus, the extensive broadening in spectrum A may be related to a strong intermolecular aggregation within the solid state of the BZI system.

The listed summary in Table 2 under the XH stretching modes section indicates that the other solid-state fundamentals are related to $\mathrm{CH}$ stretching vibrational modes. Comparison between the values of these modes and their gaslike values indicates that the 2926 and $3038 \mathrm{~cm}^{-1}$ modes show very high fd values of about 162 and $107 \mathrm{~cm}^{-1}$, respectively. Mode $3038 \mathrm{~cm}^{-1}$ is assigned as Im-CH stretching vibrations and $2926 \mathrm{~cm}^{-1}$ is a $\mathrm{Bz}-\mathrm{CH}$ stretching vibration. The deviation of these modes can be related to the hydrogen bond effect that takes place at the Im ring site. For $2926 \mathrm{~cm}^{-1}$ mode, the observed deviation is most probably related to the crystal packing and/or the molecular aggregation because it is assigned as a Bz-CH's stretching vibration. This deviation is further evidence of distortions in the $\mathrm{CH}$ bond lengths and $\mathrm{CCH}$ bond angles of benzene part.

On the other hand, for the solid and gaslike phases the frequencies 3062, 3094, and $3115 \mathrm{~cm}^{-1}$ are in very good agreement if not identical. These modes have an mfd value relative to the BLYP/6-31G* calculated values equal to $28 \mathrm{~cm}^{-1}$ that is improved to about $5.7 \mathrm{~cm}^{-1}$ after applying the reported ${ }^{42}$ scaling factor 0.995 . The application of the scaling factor on the calculated XH stretching modes makes the BLYP/6-31G* level of calculation again the best level of calculation among these investigated.

\section{Conclusion}

The experimental results obtained in this and previous studies of the BZI system compared to its theoretical data allowed us to derive correlations between the observed frequency deviations of certain modes and hydrogen bonding interaction or other molecule-molecule interactions. The study shows different trends in the calculated bond length and bond angle discrepancies from the $\mathrm{X}$-ray parameters. The $\mathrm{CH}$ bond lengths and $\mathrm{CCH}$ bond angles are found to be very sensitive to these correlations. Moreover, the predicted vibrations show that DFT methods reproduce experimental vibrational frequencies with higher accuracy than do the HF calculations, a result in good agreement with the previous studies. ${ }^{42}$ The computed values also indicate that the nonscaled BLYP/6-31G* level of calculation gives the best estimates of fundamentals compared to both solid and/or gaslike samples, including the lowest mfd values except for the $\mathrm{XH}$ stretching modes, which need to be scaled with a scaling factor of 0.995 . Finally, the study indicates that the nonscaled BLYP/6-31G* level of calculation may be used as reference values for identifying the intermolecular hydrogen bonding effect and any other molecule-molecule interactions.

Acknowledgment. We gratefully acknowledge the support of King Fahd University of Petroleum and Minerals.

Supporting Information Available: Figure 1S represents the high-resolution polarized Raman spectra from a single crystal of BZI compared to Raman spectrum of polycrystalline BZI in the $100-1700 \mathrm{~cm}^{-1}$ range. Tables $1 \mathrm{~S}, 2 \mathrm{~S}$, and $3 \mathrm{~S}$ present a comprehensive summary of the observed fundamental frequencies of benzimidazole. They also include the estimated values of these fundamentals, their scaled values, intensities, and the corresponding IR-vector graphical representation for the optimized geometries of single BZI molecule at each ab initio level used in this study. These materials are available free of charge via the Internet at http://pubs.acs.org.

\section{References and Notes}

(1) White, A. W.; Almassy, R.; Calvert, A. H.; Curtin, N. J.; Griffin, R. J.; Hostomsky, Z.; Maegley, K.; Newell, D. R.; Srinivasan, S.; Golding, B. T. J. Med. Chem. 2000, 43, 4084-4097.

(2) Chen, J. J.; Wei, Y.; Drach, J. C.; Townsend, L. B. J. Med. Chem. 2000, 43, 2449-2456. 
(3) Tapia, I.; Alonso-Cires, L.; López-Tudanca, P. L.; Mosquera, R.; Labeaga, L.; Innerárity, A.; Orjales, A. J. Med. Chem. 1999, 42, 28702880 .

(4) Sjöström, J. J. Med. Chem. 1998, 41, 1777-1788.

(5) Townsend, L. B. J. Med. Chem. 1998, 41, 1252-1262.

(6) Tang, J. C. J. Med. Chem. 1997, 40, 3937-3946.

(7) Wilson, W. D. J. Med. Chem. 1996, 39, 1452-1462.

(8) Carrière, F. Chem. Mater. 1997, 9, 1989-1993.

(9) Yamamoto, T. Macromolecules 1998, 31, 6063-6070.

(10) Hedrick, J. L. Macromolecules 1996, 29, 7335-7341.

(11) Brown, G. P.; Aftergut, S. J. Polym. Sci., Part A 1964, 2, 1839.

(12) Christov, M. Langmuir 1996, 12, 2083-2089 and references therein.

(13) Tompkins, H. G.; Sharma, S. P. Surf. Interface Anal. 1982, 4, 261.

(14) Hobbins, N. D.; Roberts, R. F. Surf. Technol. 1979, 9, 235.

(15) Thibault, S. Corros. Sci. 1977, 17, 701.

(16) Mohan, S.; Sundaragan, J.; Mink, J. Thermochim. Acta A 1991, $47,1111$.

(17) Suwaiyan, A.; Zwarich, R.; Baig, N. J. Raman Spectrosc. 1990, $21,243$.

(18) Tompkins, H. G.; Allara, D. L.; Pasteur, G. A. Surf. Interface Anal. 1983, $5,101-104$.

(19) Cordes, M. M.; Walter, J. L. Spectrochim. Acta 1968, 24, 1421.

(20) Varsanyi, G. Assignments for Vibrational Spectra of Seven Hundred Benzene Derivatives; John Wiley \& Sons: New York, 1974; Vol. 1.

(21) Santra, S.; Krishnamoorthy, G.; Dogra, S. K. J. Phys. Chem. A 2000, 104, 476-482.

(22) Luque, F. J. J. Phys. Chem. A 1999, 103, 4525-4532.

(23) Warner, I. M. J. Phys. Chem. A 1997, 101, 5296-5301.

(24) Borach, B.; Wood, J. L. Can. J. Chem. 1976, 54, 2470.

(25) Schoone, K.; Smets, J.; Houben, L.; Van Bael, M. K.; Adamowicz, L.; Maes, G. J. Phys. Chem. B 1998, 102, 4863.

(26) Suwaiyan, A.; Morsy, M. A. Spectrochim. Acta Part A 1997, 53, $575-588$.

(27) Morsy, M. A.; Al-Somali, A. M.; Suwaiyan, A. J. Phys. Chem. B 1999, 103, 11205-11210.

(28) Morsy, M. A.; Oweimreen, G. A.; Al-Tawfig, A. M. J. Phys. Chem. B 1998, 102, 3684-3691.

(29) Frisch, M. J.; Trucks, G. W.; Schlegel, H. B.; Scuseria, G. E.; Robb, M. A.; Cheeseman, J. R.; Zakrzewski, V. G.; Montgomery, J. A., Jr.; Stratmann, R. E.; Burant, J. C.; Dapprich, S.; Millam, J. M.; Daniels, A. D.; Kudin, K. N.; Strain, M. C.; Farkas, O.; Tomasi, J.; Barone, V.; Cossi, M.; Cammi, R.; Mennucci, B.; Pomelli, C.; Adamo, C.; Clifford, S.; Ochterski, J.; Petersson, G. A.; Ayala, P. Y.; Cui, Q.; Morokuma, K.; Malick,
D. K.; Rabuck, A. D.; Raghavachari, K.; Foresman, J. B.; Cioslowski, J.; Ortiz, J. V.; Stefanov, B. B.; Liu, G.; Liashenko, A.; Piskorz, P.; Komaromi, I.; Gomperts, R.; Martin, R. L.; Fox, D. J.; Keith, T.; Al-Laham, M. A.; Peng, C. Y.; Nanayakkara, A.; Gonzalez, C.; Challacombe, M.; Gill, P. M. W.; Johnson, B. G.; Chen, W.; Wong, M. W.; Andres, J. L.; Head-Gordon, M.; Replogle, E. S.; Pople, J. A. Gaussian 98, revision A.7; Gaussian, Inc.: Pittsburgh, PA, 1998.

(30) Dik-Edixhoven, C. J.; Schent, H.; van der Meer, H. Cryst. Struct. Commun. 1973, 2, 1647.

(31) Foresman, J. B.; Frisch, A. Exploring Chemistry with Electronic Structure Methods: A Guide to Using Gaussian; Gaussian: Pittsburgh, PA, 1996.

(32) Pongor, G.; Fogarasi, G.; Boggs, J. E. J. Mol. Spectrosc. 1985, $114,445$.

(33) Pongor, G.; Fogarasi, G.; Boggs, J. E. J. Am. Chem. Soc. 1985, $107,6487$.

(34) Xie, Y.; Fan, K.; Boggs, J. E. Mol. Phys. 1986, 58, 401.

(35) Fan, K.; Xie, Y.; Boggs, J. E. THEOCHEM 1986, 136, 339.

(36) Lee, S. Y.; Boo, B. H. J. Phys. Chem. 1996, 100, 15073-15078.

(37) Majoube, M.; Vergoten, G. J. Raman Spectrosc. 1992, 23, 431.

(38) Devlin, F. J.; Finley, J. W.; Stephens, P. J.; Frisch, M. J. J. Phys. Chem. 1995, 99, 16883.

(39) Handy, N. C.; Murray, C. W.; Amos, R. D. J. Phys. Chem. 1993, 97, 4392 .

(40) El-Azhary, A. A.; Suter, H. U. J. Phys. Chem. 1995, 99, 12751. (41) Wheeless, C. J. M.; Zhou, X.; Liu, R. J. Phys. Chem. 1995, 99, 12488

(42) Rauhut, G.; Pulay, P. J. Phys. Chem. 1995, 99, 3093.

(43) Johnson, B. G.; Gill, P. M. W.; Pople, J. A. J. Chem. Phys. 1993, 98,5612 .

(44) Langhoff, S. R. J. Phys. Chem. 1996, 100, 2819.

(45) HyperChem Ver. 6.01 Molecular Modeling System runs under MSWindows; HyperCube Inc.: Gainesville, FL, 2000.

(46) The FreqChk utility under GAUSSIAN 98W has two distinct modes of operation: (a) retrieving frequencies and thermodynamics data from a checkpoint file or (b) preparing a molecular modeling file and a script file for HyperChem program to visualize and animate the computed normal vibrational modes.

(47) Gerdil, R. Acta Crystallogr. 1961, 14, 333.

(48) Jeffrey, G. A.; Ruble, J. R.; Yates, J. H. Acta Crystallogr. 1983 B39, 388 .

(49) Ferenczy, G.; Harsanyi, L.; Rozasondai, B.; Hargittai, I. J. Mol. Struct. 1986, 140, 71 . 